\title{
Training During the COVID-19 Lockdown: Knowledge, Beliefs, and Practices of 12,526 Athletes from 142 Countries and Six Continents
}

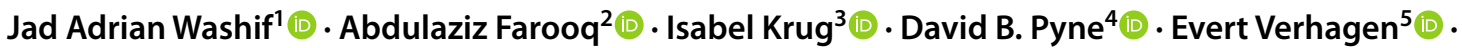

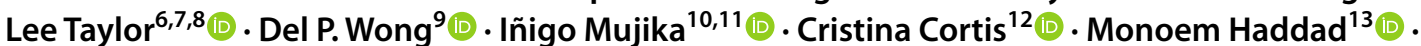
Omid Ahmadian ${ }^{14}$ - Mahmood Al Jufaili ${ }^{15}$ (1) Ramzi A. Al-Horani ${ }^{16}$ (1) - Abdulla Saeed Al-Mohannadi ${ }^{17}$ (1) .

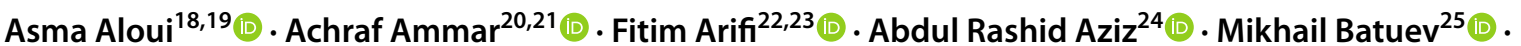
Christopher Martyn Beaven ${ }^{26}$ - Ralph Beneke ${ }^{27} \cdot$ Arben Bici $^{28} \cdot$ Pallawi Bishnoi $^{29} \cdot$ Lone Bogwasi $^{30,31}$.

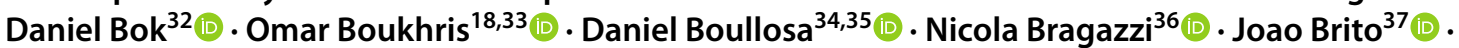
Roxana Paola Palacios Cartagena ${ }^{38} \cdot$ Anis Chaouachi $^{39,40}$. Stephen S. Cheung ${ }^{41}$ (1) Hamdi Chtourou ${ }^{18,33}$ (D) Germina Cosma ${ }^{42}$ (1) Tadej Debevec ${ }^{43,44}$ (1) - Matthew D. DeLang ${ }^{45}$. Alexandre Dellal ${ }^{46,47}$. Gürhan Dönmez ${ }^{48}$ (1) Tarak Driss $^{21}$ (1) Juan David Peña Duque ${ }^{49} \cdot$ Cristiano Eirale $^{50} \cdot$ Mohamed Elloumi $^{51}$ (D) Carl Foster $^{52}$.

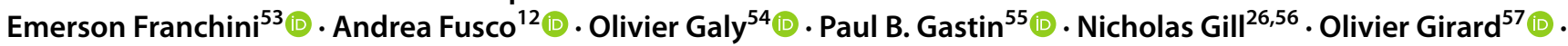

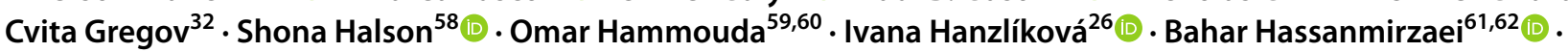

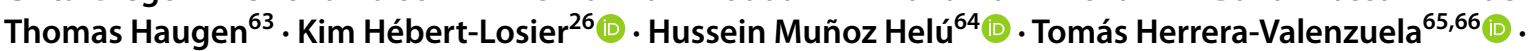

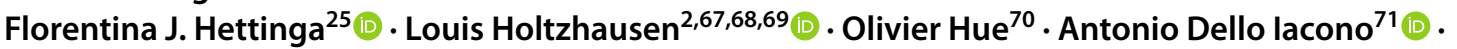

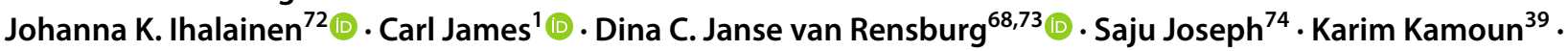
Mehdi Khaled ${ }^{75}$ (1) $\cdot$ Karim Khalladi ${ }^{2}$ - Kwang Joon Kim ${ }^{76} \cdot$ Lian-Yee Kok $^{77} \cdot$ Lewis MacMillan $^{78}$ (D) Leonardo Jose Mataruna-Dos-Santos ${ }^{79,80,81}$ ( Ryo Matsunaga ${ }^{82,83} \cdot$ Shpresa Memishi $^{84} \cdot$ Grégoire P. Millet $^{85}$ (1) Imen Moussa-Chamari ${ }^{13}$ ([) $\cdot$ Danladi Ibrahim Musa ${ }^{86}$ (b) Hoang Minh Thuan Nguyen ${ }^{87} \cdot$ Pantelis T. Nikolaidis $^{88}$ (i) Adam Owen ${ }^{89,90}$. Johnny Padulo ${ }^{91}$ (1) . Jeffrey Cayaban Pagaduan ${ }^{92} \cdot$ Nirmala Panagodage Perera ${ }^{93,94,95}$ (1) . Jorge Pérez-Gómez ${ }^{96}$ (1) Lervasen Pillay ${ }^{68,97}$ - Arporn Popa ${ }^{98}$. Avishkar Pudasaini ${ }^{99}$. Alireza Rabbani ${ }^{100}{ }^{0}$. Tandiyo Rahayu ${ }^{101}$ (1) Mohamed Romdhani ${ }^{18}$. $\cdot$ Paul Salamh ${ }^{102} \cdot$ Abu-Sufian Sarkar ${ }^{103} \cdot$ Andy Schillinger ${ }^{104}$.

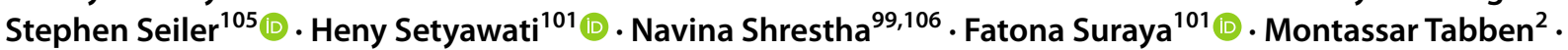
Khaled Trabelsi ${ }^{33,107}$ (1) Axel Urhausen ${ }^{108,109,110}$ - Maarit Valtonen ${ }^{111}$ (1) . Johanna Weber ${ }^{112,113}$ (1)

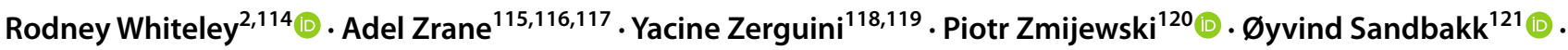
Helmi Ben Saad ${ }^{122,123}$ (1) Karim Chamari²

Accepted: 23 September 2021 / Published online: 23 October 2021

(c) The Author(s) 2021

\begin{abstract}
Objective Our objective was to explore the training-related knowledge, beliefs, and practices of athletes and the influence of lockdowns in response to the coronavirus disease 2019 (COVID-19) pandemic caused by severe acute respiratory syndrome coronavirus 2 (SARS-CoV-2).

Methods Athletes ( $n=12,526$, comprising 13\% world class, $21 \%$ international, $36 \%$ national, $24 \%$ state, and $6 \%$ recreational) completed an online survey that was available from 17 May to 5 July 2020 and explored their training behaviors (training knowledge, beliefs/attitudes, and practices), including specific questions on their training intensity, frequency, and session duration before and during lockdown (March-June 2020).

Results Overall, 85\% of athletes wanted to "maintain training," and 79\% disagreed with the statement that it is "okay to not train during lockdown," with a greater prevalence for both in higher-level athletes. In total, $60 \%$ of athletes considered "coaching by correspondence (remote coaching)" to be sufficient (highest amongst world-class athletes). During lockdown, <40\% were able to maintain sport-specific training (e.g., long endurance [39\%], interval training [35\%], weightlifting [33\%],
\end{abstract}

Extended author information available on the last page of the article 
plyometric exercise [30\%]) at pre-lockdown levels (higher among world-class, international, and national athletes), with most (83\%) training for "general fitness and health maintenance" during lockdown. Athletes trained alone (80\%) and focused on bodyweight (65\%) and cardiovascular (59\%) exercise/training during lockdown. Compared with before lockdown, most athletes reported reduced training frequency (from between five and seven sessions per week to four or fewer), shorter training sessions (from $\geq 60$ to $<60 \mathrm{~min}$ ), and lower sport-specific intensity ( $38 \%$ reduction), irrespective of athlete classification. Conclusions COVID-19-related lockdowns saw marked reductions in athletic training specificity, intensity, frequency, and duration, with notable within-sample differences (by athlete classification). Higher classification athletes had the strongest desire to "maintain" training and the greatest opposition to "not training" during lockdowns. These higher classification athletes retained training specificity to a greater degree than others, probably because of preferential access to limited training resources. More higher classification athletes considered "coaching by correspondence" as sufficient than did lower classification athletes. These lockdown-mediated changes in training were not conducive to maintenance or progression of athletes' physical capacities and were also likely detrimental to athletes' mental health. These data can be used by policy makers, athletes, and their multidisciplinary teams to modulate their practice, with a degree of individualization, in the current and continued pandemic-related scenario. Furthermore, the data may drive training-related educational resources for athletes and their multidisciplinary teams. Such upskilling would provide athletes with evidence to inform their training modifications in response to germane situations (e.g., COVID related, injury, and illness).

\section{Key Points}

Higher classification athletes have superior knowledge and beliefs/attitudes regarding training, although these were ranked predominately as "moderate," suggesting that training-related evidence may not penetrate all athletes to a "good" level.

During lockdown, most athletes trained alone and focused on general health and well-being rather than with sport or discipline specificity, partly because of a lack of resource such as space, equipment, facilities, and multidisciplinary support teams, with such access favoring higher classification athletes.

The challenges athletes experienced during lockdown reduced their motivation, which was amplified by the lack of competition. Athletes/coaches may benefit from arrangements that permit training and competition during lockdown (even if home based).

Although higher classification athletes coped better in general, all athletes reported substantial reductions in key training variables, including frequency, duration, intensity, and type.

"Remote"-based practices using digitally mediated technology for coaching/training emerged, appeared effective, and were best received by higher classification athletes.

Information resources (e.g., easily accessible online seminars and discussions) are necessary for athletes to improve knowledge and beliefs/attitudes.

\section{Introduction}

The coronavirus disease 2019 (COVID-19) pandemic caused by severe acute respiratory syndrome coronavirus 2 (SARS-CoV-2) compromised the ability of many populations to engage in physical activity and benefit from sport participation [1]. Both recreational and elite competition schedules were decimated by postponements and cancellations, including the 2020 Tokyo Olympic Games. Athlete training was compromised for numerous reasons, most crucially the periods of recurring local/national lockdowns (including movement restrictions, social distancing, and facility closures). Closures of specialist athlete training facilities were widespread, hindering athlete access to these and their multidisciplinary teams (e.g., coaches, sports science, medical and allied health professionals) $[2,3]$. Team or contact sports have been particularly challenged because social distancing prevents physical interaction and much team-based technical and tactical training [4]. In combination, these challenges have compromised the ability of high-performance athletes to conduct their physical, technical, or tactical training [5].

To comply with lockdown restrictions, many creativeoften home-based-training solutions were employed in attempts to facilitate appropriate training load, maintain/ progress physical and technical qualities, and minimize injury risk [2, 5-8]. Performing these exercises during lockdown could also boost immunity and anti-inflammatory effects (reduced risk of disease) in response to respiratory pathogens such as seasonal influenza [9]. This pandemic-associated lockdown could have negative physical consequences, including reduced maximal oxygen consumption, endurance capacity, muscular strength, and muscle mass [10]. Mental health can also be adversely affected by the stress or anxiety experienced in isolation 
during lockdown [11]. Limited data regarding altered athlete training practice in response to lockdown have emerged, albeit specific to one country (South Africa) experiencing a high COVID-19 burden [5]. Here, athletes of different classifications (elite and subelite) reported training at altered moderate intensities for reduced session lengths during lockdown [5]. Substantial reductions in weekly training frequency and time were reported among collegiate-level athletes from different sports [12]. More recently, a worldwide study within handball reported reduced physical activity and increased sedentary behavior, regardless of the athlete's competitive level [13].

Some general guidelines for physical activity during lockdown have been suggested [14], although these indirectly touched upon exercise without empirical data on athletes' training practices. Other recommendations were largely generic and likely insufficient for different levels of athletes, such as state and world-class levels [15, 16]. During early phases of the pandemic, "return to sport" considerations were focused on higher-level athletes [3, 17]. These studies provided useful insights related to the safety of training and competition during the pandemic but fell short of evidence-based guidelines for athletes across all competitive levels.

Athletes' experience may be conceptualized as the extent to which they engage in exercise, training, and competition [18]. During lockdown, athletes may be more dependent on themselves, instead of on their coach, which further supports the importance of self-regulation ability (e.g., metacognitively, motivations, and actions) [19]. In this context, self-efficacy may be thought of as a motivational mechanism for self-regulated learners, which refers to a person's beliefs in their abilities to think and act in ways that progress them towards their learning goals [20]. Additionally, personal beliefs could act as a placebo that impacts on training routines [21]. Among adults, knowledge of both aerobic and muscular types of physical activity recommendations was positively associated with physical fitness variables [22]. Similarly, positive attitudes were associated with being physically active [23], whereas having positive attitudes and beliefs about exercise or being physically active for health predicted physical activity participation [24]. Likewise, athletes' concerns over reduced fitness and abilities could have influenced their attitudes toward training during lockdown. Based on these premises, an athlete's ability to successfully react to the training-related challenges of COVID-19 and modify their practice (e.g., training intensity, volume, frequency, and mode) could be influenced by their existing knowledge of and beliefs or attitudes about training. Thus, identifying the knowledge, beliefs, and attitudes of athletes related to training and training interruptions (including COVID-19), while accounting for athlete classification, their adaptive responses to training (i.e., those with higher self-regulatory skills would train more), and degree of remote coaching and practices, is warranted.

Globally derived data from a variety of athletes (world class or otherwise) are required to elucidate the effects of lockdown on their training practices. Such evidence may help policy makers, the athletes, and their multidisciplinary teams modulate their practice, with a degree of individualization, in the current and continued COVIDrelated scenario [25]. Understanding how public health measures influence athletes may help better prepare sports medicine and support teams for similar situations in the future. For these reasons, we characterized the athletes' knowledge and beliefs/attitudes related to training disruptions and practices during the COVID-19 lockdown in a large global sample, including comparisons between athlete classifications (e.g., world-class, national, and state-level athletes).

\section{Methods}

\subsection{Design and Participants}

Participants provided informed consent, and the study received ethical approvals from the University of Melbourne Human Research Ethics Committee (HREC; no. 2056955.1), Qatar University (QU-IRB 1346-EA/20), and the University of Cassino e Lazio Meridionale (10031) in the spirit of the Declaration of Helsinki. Data were collected and processed anonymously and according to the guidelines of the "General Data Protection Regulation" (gdpr-info.eu). Participation was voluntary, and all individuals were permitted to withdraw at any time before completion and submission of the survey. Participant eligibility criteria were as follows: (1) eliteor subelite athletes aged $\geq 18$ years of either sex with or without disability; (2) athletes experienced at least two consecutive weeks of lockdown (March-June 2020); (3) athletes had not missed training for $\leq 7$ days because of illness/injury within the survey period; and (4) athletes experienced a "medium-to-high" lockdown severity. A medium-high lockdown severity was considered met when one or more of the following criteria were fulfilled: (1) movement was permitted only for essential supplies and groceries, (2) access to public exercise facilities was restricted (i.e., recreational areas such as parks or open spaces were closed or time/capacity limits were imposed), and (3) training facilities at institutions, clubs, colleges, etc. were closed. The a priori sample size estimation was 12,418 (see the supplementary material S1). In total, 13,772 entries were evident upon 
survey closure. After exclusions $(n=1246)$ for duplicates $(n=731)$, age limit violations $(n=410)$, and/or unmet lockdown severity criteria $(n=105)$ were completed, a final sample of data from 12,526 athletes (142 countries/ territories across six continents) was used for subsequent statistical modeling. The sample represented 108 "team" and "individual" sports.

\subsection{Protocols and Questionnaires}

\subsubsection{Data Collection}

An online survey was administered and disseminated via Google Forms from 17 May to 5 July 2020. The survey was shared via email and personal/group messaging applications (e.g., WhatsApp, Signal, and Telegram) and promoted on social media (e.g., Facebook, Twitter, and Instagram) through the professional networks of the research team (e.g., clubs, federations, and institutions). The English language "master" version of the survey was translated and administered in 34 further languages: Albanian, Arabic, Bangla, Chinese-simplified, Chinese-traditional, Croatian, Czech, Danish, Finnish, French, German, Greek, Hindi, Indonesian, Italian, Japanese, Korean, Malay, Nepalese, Norwegian, Persian, Polish, Portuguese, Punjabi, Romanian, Russian, Sinhala, Slovenian, Spanish, Swahili, Swedish, Thai, Turkish, and Vietnamese. The survey questions underwent translation and back-translation, performed by the research team (including at least one native speaker and one topic expert), including pilot completions of the survey by and feedback from native language speaking athletes, resulting in the finalized surveys for all languages.

Data from questions with preset answers (i.e., predefined multiple choice) were converted directly into standardized codes/numbers using an automated/customized setting on the Excel spreadsheet (Microsoft Corporation; Redmond, WA, USA); all automated responses were checked for veracity. Remaining data (i.e., free-text answers) underwent theme analysis/aggregation (all non-English responses were back-translated to English first), and subsequent themes were re-classified into standardized codes/numbers to facilitate statistical modeling. Test-retest reliability was determined within an English-speaking participant subgroup $(n=129)$, under the same conditions, twice (separated by $9 \pm 4$ days), with Cronbach's alpha (0.82-0.97) rated as good to excellent [26].

\subsubsection{Survey Questionnaire}

The survey was initially developed by the first and senior author and then reviewed by the wider authorship team (e.g., research team), involving $>100$ researchers (from $>60$ countries). The 59 questions explored athletes' training knowledge, beliefs/attitudes, and practices, including specific questions (intensity, frequency, and session duration) on their training before and during lockdown, within a structure of four sections (see the ESM in conjunction with the following text/section (Sect.) for specific questions in the present study).

(a) Athlete details (11 questions): Athlete classification: (1) Olympic Games, world championships, or equivalent (categorized as world class); (2) other international events (international); (3) national; (4) state or province (state); and (5) others (recreational).

(b) Athlete knowledge (ten questions). Athletes' views (what was known) on training disruptions during lockdown and its associated effects were assessed. A 5-point Likert scale ( $1=$ "strongly agree" to $5=$ "strongly disagree" and $6=$ "don't know") established (1) general training knowledge (e.g., training volume and intensity required to maintain fitness); and (2) how athletes attempted to continue their training during lockdown and thus how lockdown affected their training.

(c) Athletes' beliefs and attitudes (14 questions): How the athletes perceived training interruptions during lockdown and their implications for training. Specifically, the athletes expressed what they thought or believed and how they behaved optimistically (attitude) towards key issues. The same 5-point Likert scale explored athletes' perceptions of fitness, mental health and emotion, coaching interaction, desire to train, and motivation.

(d) Training practices (ten questions): An array of question styles was used to establish training practices, including (1) selecting one or more predefined answers; (2) comparing related before and during lockdown effects on training practices; (3) yes or no; and (4) sub-questions including a free-text cell to capture nuanced detail.

A scoring system was developed where knowledge (Sect. b) had nine scored questions (scoring range: 0-9) and beliefs/ attitudes (Sect. c) had seven scored questions (scoring range: 0-7). Correct (for knowledge) or positive (for beliefs/attitudes) answers (e.g., strongly agree/agree or strongly disagree/disagree with a statement) were scored as " 1. " The other answers received a score of "0" (including the statements "neutral" or "don't know"). The total score was used to rank the level of knowledge and beliefs/attitudes (i.e., $\geq 70 \%$ as good, 51 to $<70 \%$ as moderate, and $\leq 50 \%$ as poor), as used previously [27, $28]$ to compare athletes of different classifications. 


\subsection{Statistical Analysis}

All data were coded and statistical analyses performed using SPSS v. 23 (IBM; Armonk, NY, USA). Data are presented using a variety of appropriate descriptive statistics, including frequencies, percentages, and mean \pm standard deviation. Knowledge and belief/attitude scores between athlete classifications were modeled using a one-way analysis of variation and effect size $\left(\eta^{2}\right)$ with a Bonferroni analysis post hoc if indicated. The chi-squared test was used to compare categorical variables between athlete classifications. Adjusted standardized residuals from the chi-squared tests were interpreted to determine significant associations. Pearson's correlation coefficient $(r)$ analysis was used to examine the associations between knowledge and belief/attitude scores, and between knowledge and training variables (frequency, duration, and intensity) and belief/attitude and training variables. Two-tailed alpha was $<0.05$.

\section{Results}

\subsection{Demographic}

Table 1 shows the demographic characteristics of athletes. Athletes were predominantly men (66\%), aged 18-29 years (67\%), from 108 sports. Most (83\%) had experienced lockdown for 5-12 weeks at survey completion, with twothirds (67\%) permitted to exercise only at home (Table 2).

\subsection{Knowledge and Beliefs/Attitudes}

The results for questions related to knowledge (S2) and beliefs/attitudes (S3) used for the summed scores (interpretive thresholds [e.g., moderate] described previously) are presented in the ESM. Summed knowledge and belief/ attitude scores related to training interruptions were 57 and $55 \%$, respectively (considered moderate), with generally higher scores in higher classification athletes $(p<0.05)$ (Table 3).

Athlete classification was positively associated with knowledge $(p<0.05)$, except for "training frequency" $(p=0.073)$ (S4, question 4 [Q4]). Athletes (particularly national athletes) "agreed" (39\%) or "strongly agreed" (29\%) that lockdown limited training and potentially reduced fitness (Q1), but athletes "disagreed" (37\%) or "strongly disagreed" (25\%; particularly "world-class" athletes $[p<0.05])$ that "normal" training was possible during lockdown (Q7), see S4. Many athletes $(60 \%$, with the highest among worldclass athletes) considered "coaching by correspondence (remote coaching)" to be sufficient.

Additionally, knowledge was positively correlated with beliefs/attitudes $(r=0.41)$, but there was little association
Table 1 Demographic characteristics of participants $(n=12,526)$

\begin{tabular}{|c|c|}
\hline Characteristics & Number (\%) \\
\hline \multicolumn{2}{|l|}{ Sex } \\
\hline Male & $8265(66)$ \\
\hline Female & $4229(34)$ \\
\hline Other & $32(0)$ \\
\hline \multicolumn{2}{|c|}{ Age category, years } \\
\hline $18-29$ & $8419(67)$ \\
\hline $30-39$ & 2431 (19) \\
\hline $40-49$ & $1078(9)$ \\
\hline $50-59$ & $468(4)$ \\
\hline$\geq 60$ & $121(1)$ \\
\hline Missing & $9(-)$ \\
\hline \multicolumn{2}{|l|}{ Continent } \\
\hline Asia & $4777(38)$ \\
\hline Europe & $4305(34)$ \\
\hline Africa & $1375(11)$ \\
\hline South America & $973(8)$ \\
\hline North America & $907(7)$ \\
\hline Oceania & $189(2)$ \\
\hline \multicolumn{2}{|l|}{ Athlete's status } \\
\hline Amateur & $6453(51)$ \\
\hline Semiprofessional & $2765(22)$ \\
\hline Professional & $3222(26)$ \\
\hline Other & $86(1)$ \\
\hline \multicolumn{2}{|l|}{ Main sports } \\
\hline Soccer & $2696(22)$ \\
\hline Athletics & $1306(10)$ \\
\hline Cycling & $679(5)$ \\
\hline Volleyball & $602(5)$ \\
\hline Basketball & $522(4)$ \\
\hline Triathlon & $503(4)$ \\
\hline Handball & $403(3)$ \\
\hline Rugby & $365(3)$ \\
\hline Swimming & $348(3)$ \\
\hline Judo & $313(3)$ \\
\hline Taekwondo & $254(2)$ \\
\hline Hockey & $210(2)$ \\
\hline Futsal & $198(2)$ \\
\hline Karate & $165(1)$ \\
\hline Baseball/Softball & $159(1)$ \\
\hline Netball & $145(1)$ \\
\hline Rowing & $130(1)$ \\
\hline Bodybuilding & $130(1)$ \\
\hline Cricket & $124(1)$ \\
\hline Fencing & $121(1)$ \\
\hline Other sports & $3153(25)$ \\
\hline \multicolumn{2}{|c|}{ Sports experience, years } \\
\hline$\leq 3$ & $1476(12)$ \\
\hline $4-9$ & $4191(34)$ \\
\hline $10-19$ & $5055(41)$ \\
\hline$\geq 20$ & $1645(13)$ \\
\hline
\end{tabular}


Table 1 (continued)

\begin{tabular}{ll}
\hline Characteristics & Number $(\%)$ \\
\hline Missing & $159(-)$ \\
Athlete classification & \\
World class & $1674(13)$ \\
International & $2565(21)$ \\
National & $4482(36)$ \\
State & $3038(24)$ \\
Recreational & $763(6)$ \\
Missing & $4(-)$ \\
Are you currently in lockdown? & \\
Yes & $7955(64)$ \\
No & $4568(36)$ \\
Missing & $3(-)$ \\
Lockdown experience, weeks & \\
$\leq 4$ & $1809(15)$ \\
$5-8$ & $4256(35)$ \\
$9-12$ & $5839(48)$ \\
$\geq 12$ & $278(2)$ \\
Missing & $344(-)$ \\
Number of household members & \\
1 (live alone) & $815(7)$ \\
2 & $2012(16)$ \\
4 & $2468(20)$ \\
$\geq 5$ & $3376(27)$ \\
Missing & $3767(30)$ \\
& $88(-)$ \\
\hline &
\end{tabular}

with training frequency $(r=-0.03)$, duration $(r=-0.06)$, or intensity $(r=-0.08)$. Similarly, belief/attitude scores were not related to self-reported training frequency $(r=0.05)$, duration $(r=-0.002)$, or intensity $(r=-0.01)$.

\subsection{Training Practices}

Most questions were positively related to athlete classification $(p<0.05)$. During lockdown, $83 \%$ of athletes aimed to maintain or develop general fitness and health, generally $(80 \%)$ training alone (particularly world-class athletes $[p<0.05])$. Many athletes $(65 \%)$, especially world-class athletes $(p<0.05)$ used bodyweight-based exercises with limited or repurposed equipment/items. Only $<40 \%$ managed to perform specific training (e.g., long endurance and interval training) at an intensity similar to that before lockdown (more so in higher classification athletes) (Table 4). Compared with before lockdown, training frequency was reduced from between five and seven sessions per week to four or fewer during lockdown (Fig. 1a), with 70\% (before lockdown) to $\sim 42 \%$ (during lockdown) of athletes training for five or more sessions per week. A longer ( $\geq 60 \mathrm{~min}$ ) to shorter ( $<60$ min during lockdown) training duration per session was evident (Fig. 1b), although more world-class and international athletes trained for at least 90 -min periods before and during lockdown. Proportions of athletes who trained $\geq 60$ min per session were higher $(\sim 84 \%)$ before than during $(\sim 46 \%)$ lockdown. Training intensity was reduced $(\sim 38 \%)$ on average, with state athletes reporting lower training intensity $(p<0.05)$ than other athlete classifications (Fig. 2). Access to space and equipment (to facilitate technical, cardiovascular, and strength training) was related to athlete classification $(p<0.001)$, aside from strength training space/equipment ( $p=0.018)$ (Fig. 3).

\section{Discussion}

These data represent the first global study reporting the knowledge and beliefs/attitudes of athletes (classified from Olympic to recreational level) regarding training disruptions and their practices during COVID-19 lockdown (March-June 2020). During lockdown, most athletes trained alone at their own homes, focusing on bodyweight-based and/or cardiovascular training promoting general fitness and health maintenance. Higher classification athletes were better able to maintain (e.g., resource access, including equipment and space) their pre-lockdown training specificity (e.g.,
Table 2 Training and exercise during lockdown $(n=12,526)$

\begin{tabular}{lc}
\hline What the governing authority allowed during lockdown & Number (\%) \\
\hline Exercising at home only & $8330(67)$ \\
Using available spaces for exercise around my housing area/compound & $5256(42)$ \\
Outdoor cycling & $3354(27)$ \\
Running in a recreational park or stadium & $3317(27)$ \\
Outdoor hiking or trekking in non-public facilities & $2577(21)$ \\
Receive/borrow equipment from sports bodies or institutes and train at home & $2105(17)$ \\
Access to gymnasium (muscle strengthening/resistance training) & $579(5)$ \\
Access to sports academy or institute's school or university's facilities & $510(4)$ \\
Other & $100(1)$ \\
\hline
\end{tabular}

As athletes could select multiple answers for all questions, the numbers do not total 12,526 or $100 \%$ 
Table 3 Comparison of knowledge and beliefs/attitudes related to training interruptions during lockdown among athlete classification from world class to recreational $(n=12,495)$

\begin{tabular}{lll}
\hline Classification & $\begin{array}{l}\text { Knowledge (range 0-9 } \\
\text { marks) }\end{array}$ & $\begin{array}{l}\text { Beliefs/attitudes } \\
\text { (range 0-7 } \\
\text { marks) }\end{array}$ \\
\hline World class & $5.2 \pm 1.6(58 \%)$ & $3.9 \pm 1.5(56 \%)$ \\
International & $5.2 \pm 1.6(58 \%)$ & $3.9 \pm 1.6(56 \%)$ \\
National & $5.1 \pm 1.7(57 \%)$ & $3.8 \pm 1.6(54 \%)$ \\
State & $5.1 \pm 1.6(57 \%)$ & $3.9 \pm 1.6(56 \%)$ \\
Recreational & $4.8 \pm 1.8(53 \%) *$ & $3.4 \pm 1.7(49 \%) *$ \\
Total & $5.1 \pm 1.7(57 \%)$ & $3.8 \pm 1.6(54 \%)$ \\
Effect size & 0.003 & 0.005 \\
\hline
\end{tabular}

Higher scores indicate a greater number of correct (for knowledge) or positive (for beliefs/attitudes) answers (e.g., strongly agree/agree or strongly disagree/disagree with a statement); Data are mean \pm standard deviation

*Significantly different from all other athlete classifications

plyometrics, technical skill, speed endurance, long endurance, and interval training). Training session frequency altered (from between five and seven sessions to four or fewer sessions per week), with shorter training sessions $(\geq 60$ to $<60 \mathrm{~min})$ and lower sport-specific intensity $(\sim 38 \%$ reduction) for most athletes. Overall scores of knowledge and beliefs/attitudes related to training during lockdown were moderate and generally did not differ by athlete classification, except for recreational athletes, which were poor/ moderate.

Training-related information is digitally and easily accessible for most athletes. Despite this, higher classification athletes appear to have learned "more" from their sporting experiences and networks, scoring higher than recreational athletes for knowledge and beliefs/attitudes about training (Table 3). Total scores were modest (range 54-58\%; moderate; see Table 3) across all surveyed athlete classifications, aside from recreational, suggesting that training-related evidence may not penetrate the knowledge and beliefs of all athletes. For example, less than half of the athletes (47\%) indicated that endurance capacity could be maintained by doing high-intensity interval training (S2), despite demonstrated positive endurance training effects [29]. Similarly, only $30 \%$ of athletes believed that $<4$ weeks of lockdown would have little effect on their fitness levels (S3), a duration of 'no training' that may be tolerated without observing significant de-training effects [30, 31]. Athletes believed they needed "high training intensity" (71\%; significantly more among international athletes) with "high training frequency" (88\%) to maintain fitness level (S2), concurring with evidence that, to maintain or optimize endurance and strength performance effectively, training intensity must be "kept high" [30-33]. However, an important caveat is that, although strength levels can be retained for $\leq 3$ weeks without resistance training, rates of strength decay may accelerate thereafter, i.e., $\geq 5$ weeks [31]. The data and their agreement (or otherwise) with literature evidence should guide training prescriptions during periods of disruption (e.g., lockdown, illness, and injury), and it appears that palatable educational resources to this effect may be required to improve an apparent partial disconnect between the evidence-practitioner-athlete knowledge communication pathways.

During lockdown, athletes adapted to training with limited equipment and facilities [5] despite the likely low effectiveness of these approaches for optimal sports-specific training [3] and uncertain safety ramifications. In the current study, most athletes aimed to maintain/develop their general fitness/health and trained alone. Common training activities during lockdown were bodyweight exercises and cardiorespiratory training, probably because of the easy accessibility of these training modalities. Unfortunately for these athletes (in general), remote training (i.e., alone) reduced motivation (53\%), a situation amplified by the lack of competition (58\%), potentially leading to psychological issues, as reported elsewhere [34]. Such issues may be exacerbated by a lack of a "social facilitator" and encouragement [35] or simply missing interaction with team members [12]. These are substantial factors regarding social invitations for action (i.e., motivators) and athletes' sport-related decision making [36]. Accordingly, higher classification athletes preferred training through cooperative/shared programming (e.g., athlete and coach input) and were more receptive to "remote training/coaching" (60\%; highest amongst worldclass athletes), evidently recognizing this (at least in part) as somewhat effective. Therefore, while we acknowledge the importance of maintaining "fitness" and physical qualities during lockdown, it is clear that mental and motivational aspects and training safety also warrant attention.

Training with sport specificity tailored towards key competition bouts/cycles requires inherent well-orchestrated variation in the key principles of training [4, 37, 38], which was evidently challenging during lockdown. Marked reductions in training frequency, duration, and intensity relative to before lockdown were reported, disproportionately affecting lower-level athletes compared with world-class and international athletes (Figs. 1 and 2). Irrespective of athlete classification, changes (i.e., reduced) in multiple training variables can compromise an athlete's functional performance, especially if the training intensity is not maintained [30, 31, 33]. For example, among professional cyclists, changes in training volume and intensity distribution during a 7-week lockdown caused a large reduction in 5- and 20-min (maximal effort) cycling performance [39]. Total training volume decreased $(-34 \%)$, and the weekly volume of different standardized zones (i.e., zone 1 [low intensity] to zone 6 
Table 4 Athlete practices during COVID-19 lockdown

Practice

Percentage

\begin{tabular}{llllll}
\hline WC & INT & NAT & ST & REC & Overall
\end{tabular}

1. What are/were your general purpose(s) of training during the lockdown? $(n=12,385)$

To maintain/develop general fitness/health*

To maintain/develop skills/technique*

To maintain/develop strength and power*

To maintain/develop muscular endurance*

To maintain/develop abdominal strength*

To maintain/develop aerobic fitness*

To maintain/develop general flexibility*

To improve muscle balance*

Weight management*

Other*

2. Who is prescribing/prescribed the training program during the lockdown? $(n=12,351)$

Own training program*

Training program from my coach/trainer*

Combined own training and coach/trainer*

Found training material from an external source: online/social media/TV, a friend, etc.*

Other*

3. Do/did you train? $(n=12,347)$

Alone*

In a small group of partners of equal athletic capacity*

With family members or friends with little athletic capacity*

Other

4. What are the type of exercises that you are doing/have been doing consistently (at least twice a week) during lockdown? $(n=12,522)$

Bodyweight-based exercises with limited equipment*

Weightlifting/strength training with suitable equipment (dumbbells, weights, etc.)*

Technical skills (sport-specific skills)*

Imitation or simulation of the techniques of my sport*

Cardiovascular training (running, cycling, jogging, rowing), including HIIT*

Plyometric training (repeated jumping)

Other*

5. What are the types of specific training you are/were able to do with the same intensity during the lockdown (very similar to pre-lockdown)? $(n=12,522)$

Warm-up and stretching*

Weightlifting (strength) training*

Plyometric training (e.g., repeated jumping)*

Technical skills (sport specific)*

Speed training*

Speed endurance*

Long endurance*

Interval/intermittent training*

Change of directions*

Others*

$\begin{array}{llllll}84 & 83 & 81^{\mathrm{b}} & 83 & 84 & 83 \\ 44 & 44 & 44^{\mathrm{a}} & 40^{\mathrm{b}} & 33^{\mathrm{b}} & 43 \\ 56 & 58^{\mathrm{a}} & 55 & 52^{\mathrm{b}} & 45^{\mathrm{b}} & 54 \\ 57 & 58^{\mathrm{a}} & 55 & 52^{\mathrm{b}} & 49^{\mathrm{b}} & 55 \\ 50 & 52^{\mathrm{a}} & 50^{\mathrm{a}} & 43^{\mathrm{b}} & 40^{\mathrm{b}} & 48 \\ 50 & 53^{\mathrm{a}} & 51 & 46^{\mathrm{b}} & 46^{\mathrm{b}} & 50 \\ 49^{\mathrm{a}} & 49^{\mathrm{a}} & 43 & 38^{\mathrm{b}} & 39^{\mathrm{b}} & 44 \\ 39^{\mathrm{a}} & 40^{\mathrm{a}} & 36 & 34^{\mathrm{b}} & 31^{\mathrm{b}} & 36 \\ 46 & 48 & 47 & 47 & 54^{\mathrm{a}} & 48 \\ 1 & 1 & 1^{\mathrm{b}} & 1^{\mathrm{a}} & 2^{\mathrm{a}} & 1 \\ & & & & & \\ 35^{\mathrm{b}} & 34^{\mathrm{b}} & 42 & 54^{\mathrm{a}} & 54^{\mathrm{a}} & 44 \\ 46^{\mathrm{a}} & 45^{\mathrm{a}} & 42^{\mathrm{a}} & 30^{\mathrm{b}} & 30^{\mathrm{b}} & 40 \\ 44^{\mathrm{a}} & 44^{\mathrm{a}} & 37 & 29^{\mathrm{b}} & 23^{\mathrm{b}} & 36 \\ 20^{\mathrm{b}} & 25 & 24^{\mathrm{b}} & 30^{\mathrm{a}} & 30^{\mathrm{a}} & 26 \\ 0 & 0 & 0 & 1 & 2^{\mathrm{a}} & 0 \\ & & & & & \\ 82^{\mathrm{a}} & 78^{\mathrm{b}} & 78^{\mathrm{b}} & 81 & 82 & 80 \\ 31 & 32^{\mathrm{a}} & 31^{\mathrm{a}} & 25^{\mathrm{b}} & 21^{\mathrm{b}} & 29 \\ 22^{\mathrm{a}} & 19 & 18 & 18 & 18 & 19 \\ 1 & 1^{\mathrm{a}} & 1 & 1^{\mathrm{b}} & 1 & 1\end{array}$

$\begin{array}{llllll}68^{\mathrm{a}} & 66 & 64 & 64 & 56^{\mathrm{b}} & 65 \\ 40^{\mathrm{a}} & 34^{\mathrm{a}} & 31^{\mathrm{b}} & 29^{\mathrm{b}} & 26^{\mathrm{b}} & 32 \\ 41^{\mathrm{a}} & 40^{\mathrm{a}} & 37 & 33^{\mathrm{b}} & 28^{\mathrm{b}} & 36 \\ 30^{\mathrm{a}} & 27^{\mathrm{a}} & 25 & 20^{\mathrm{b}} & 21^{\mathrm{b}} & 25 \\ 65^{\mathrm{a}} & 62^{\mathrm{a}} & 59 & 56^{\mathrm{b}} & 51^{\mathrm{b}} & 59 \\ 26 & 31^{\mathrm{a}} & 28^{\mathrm{a}} & 20^{\mathrm{b}} & 15^{\mathrm{b}} & 26 \\ 1 & 1 & 1^{\mathrm{b}} & 1 & 4^{\mathrm{a}} & 1\end{array}$

Athletes could select multiple answers for all questions. Percentages within athlete classifications represent a "yes" answer relative to a "no" answer

HIIT high-intensity interval training, INT international, NAT national, REC recreational, $S T$ state, WC world class

${ }^{\text {a }}$ Significantly higher

${ }^{\mathrm{b}}$ Significantly lower

*Significant relationship with athlete classification $\left(\chi^{2}\right), p<0.05$ 

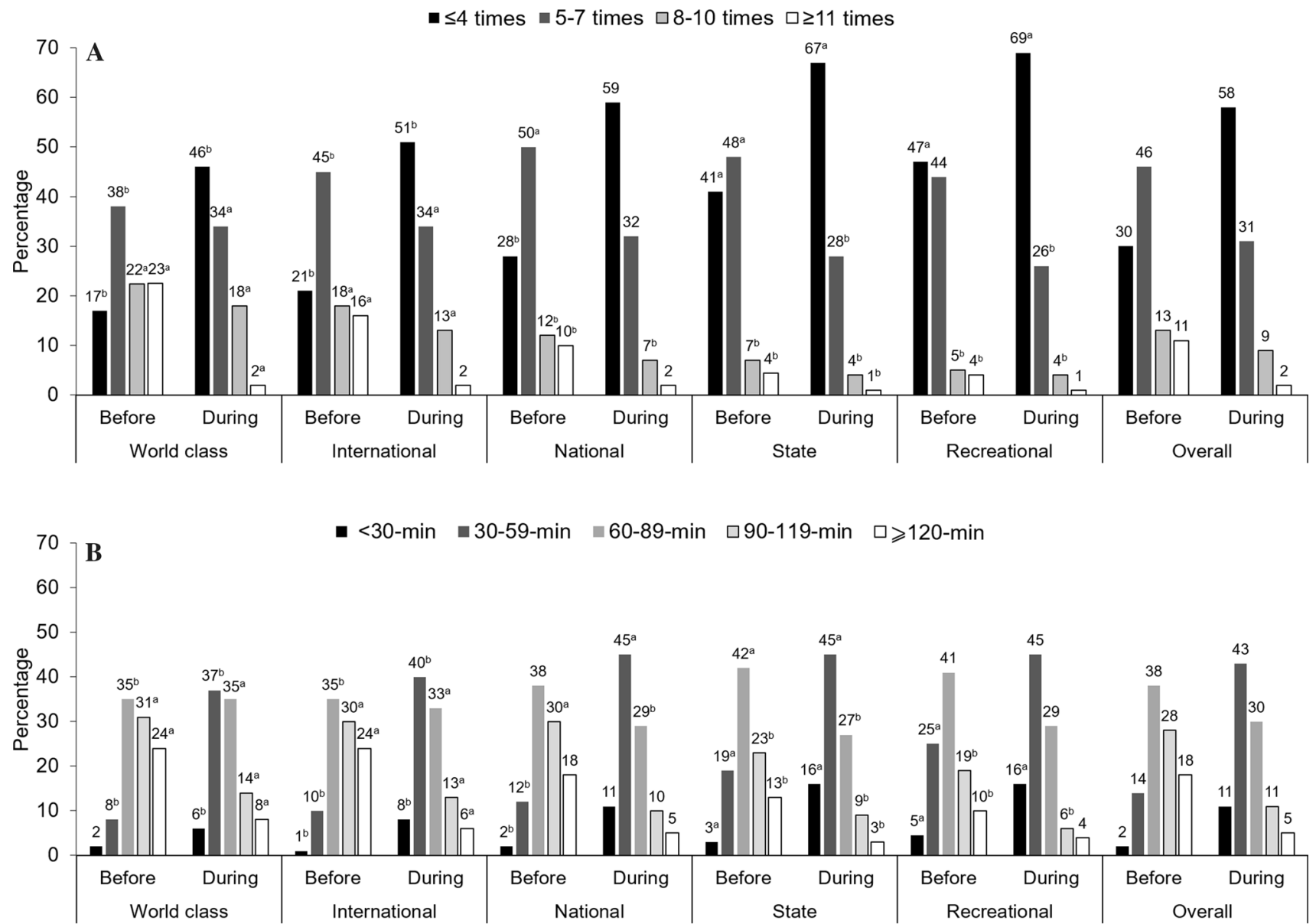

Athlete classification

Fig. 1 Training frequency and duration. A Your frequency of training sessions per week (representative of most of lockdown)? $(n=11,646)$. B How long do/did you train during each training session? $(n=10,147)$. For both training "frequency" and "duration" a significant relationship $\left(\chi^{2}\right)$ existed with the athlete classification both

[high intensity]) was largely reduced (26-52\%). Similarly, in a group of highly trained kayakers/canoeists, weekly training time and session duration reduced ( -28 and $-15 \%$, respectively), albeit with no effects on the number of specific- and non-specific sessions [38]. Professional handball players saw marked reductions in training intensity $(-54 \%)$ and volume $(-90 \%)$ [40], as alluded to within the introduction regarding the susceptibility of team sports having their training demands severely compromised by lockdown. Athletes (predominantly collegiate level, based in the USA and from a variety of sports) experienced marked reductions in weekly training frequency (i.e., $-33 \%$ who trained for five to six sessions per week) and weekly time spent completing various training-related activities such as strength training $(-1.7 \mathrm{~h})$, endurance $(-1.5 \mathrm{~h})$, mobility $(-1.1 \mathrm{~h})$, and sports specific $(-6.4 \mathrm{~h})$ with lockdown [12]. Despite these evidently troubling lockdown-mediated training-related effects, several "before" and "during" the lockdown $p<0.001 \%$, within athlete classification, represent "yes" answer, relative to "no" answer. "Significantly higher; 'Significantly lower. before indicates before lockdown, during indicates during lockdown

world records in athletics were broken during 2020-21 [44], raising questions about how certain athletes may have disproportionately benefited from lockdown, retaining a near-normal (perhaps augmented) training regimens during lockdown. Indeed, some elite athletes may have been able to execute training and recovery more effectively, facilitated in part by the reduced social, travel, and competition demands and preferential access to training equipment (e.g., weightlifting/strength training) through special arrangements (e.g., quarantine camp or training bubble) facilitating their normal (or augmented) training [3].

\subsection{Strengths, Limitations, and Future Directions}

This study and the survey design have both strengths and limitations, and the presented data should be considered accordingly. A large $(n=12,526)$ sample of athletes was 


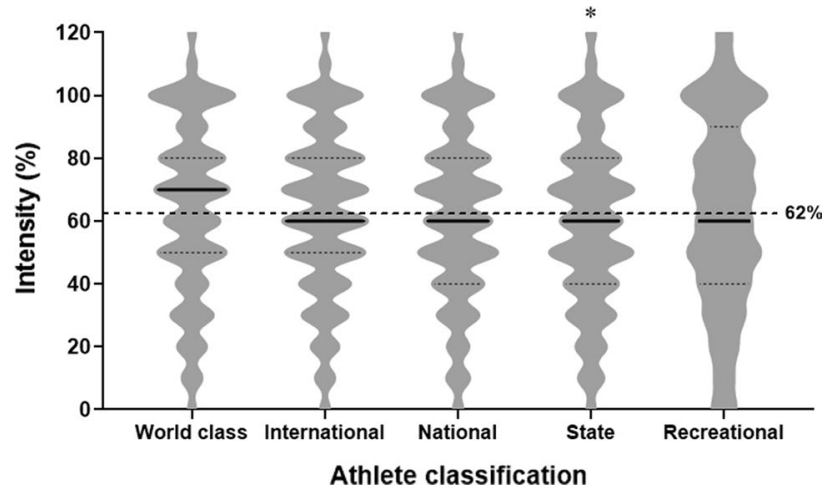

Fig. 2 Training intensity during lockdown. Question: Do/did you maintain your pre-lockdown intensity for sports-specific training (practicing your sport) during the lockdown? Can you estimate how much in percentage? (100\% represents the same intensity as before the lockdown $(N=12,518)$. The dotted line represents average intensity across athlete classification (62\%). *Significant difference from world class, international, and national. The violin plot includes a 5-point summary (lowest to highest): minimum, first quartile, median, third quartile, and maximum. The maximum or minimum number in the dataset, respectively, is shown by the upper extreme or lower extreme of the chart. Upper (third, dotted line) and lower (first; dotted line) quartiles, respectively are the 75 th and 25 th percentiles. The median (middle of data set) is shown as a line (i.e., thicker) in the center of each chart surveyed, providing a genuinely global (142 countries/ territories across six continents) context for interpretation of the research questions. However, the results are time dependent given the cross-sectional nature of the study, and the data cannot be claimed to represent causative relationships. Indeed, the study explored lockdown at the beginning of the COVID-19 pandemic (March to June 2020), with most surveyed athletes (83\%) experiencing a lockdown of 5-12 weeks during this period. Consequently, the potential for recall bias was present in some athletes; however, most questions were specific to athletes' worst experiences during lockdown. Random sampling was adopted, which would avoid recruitment bias and improve internal validity, despite the well-reported weaknesses of online surveying [41]. Whether longer periods of lockdown and/or different time periods of restrictions may have yielded different data remains unknown and requires further investigation. Customized and bespoke survey questions were used, because existing surveys/questionnaires lacked the specificity or nuance required relative to the research questions being explored (i.e., an unprecedented pandemic). However, test-retest reliability for these questions were rated as good to excellent (Cronbach's alpha 0.82-0.97). Furthermore,
Fig. 3 Reported practices for space/access and equipment to training $(n=11,451)$. Do/did you have A sufficient space/ access and $\mathbf{B}$ necessary equipment to train. Significance of relationship indicated by the chi-squared test for independence. $\%$, within athlete classification, represents a "yes" answer relative to a "no" answer. *Significant relationship with athlete classification, $p<0.05$. ${ }^{a}$ Significantly higher. ${ }^{\mathrm{b}}$ Significantly lower. Technical skills training: "cardiovascular" consisted of running, cycling, jogging, and high-intensity interval training, "strength" consisted of weightlifting training
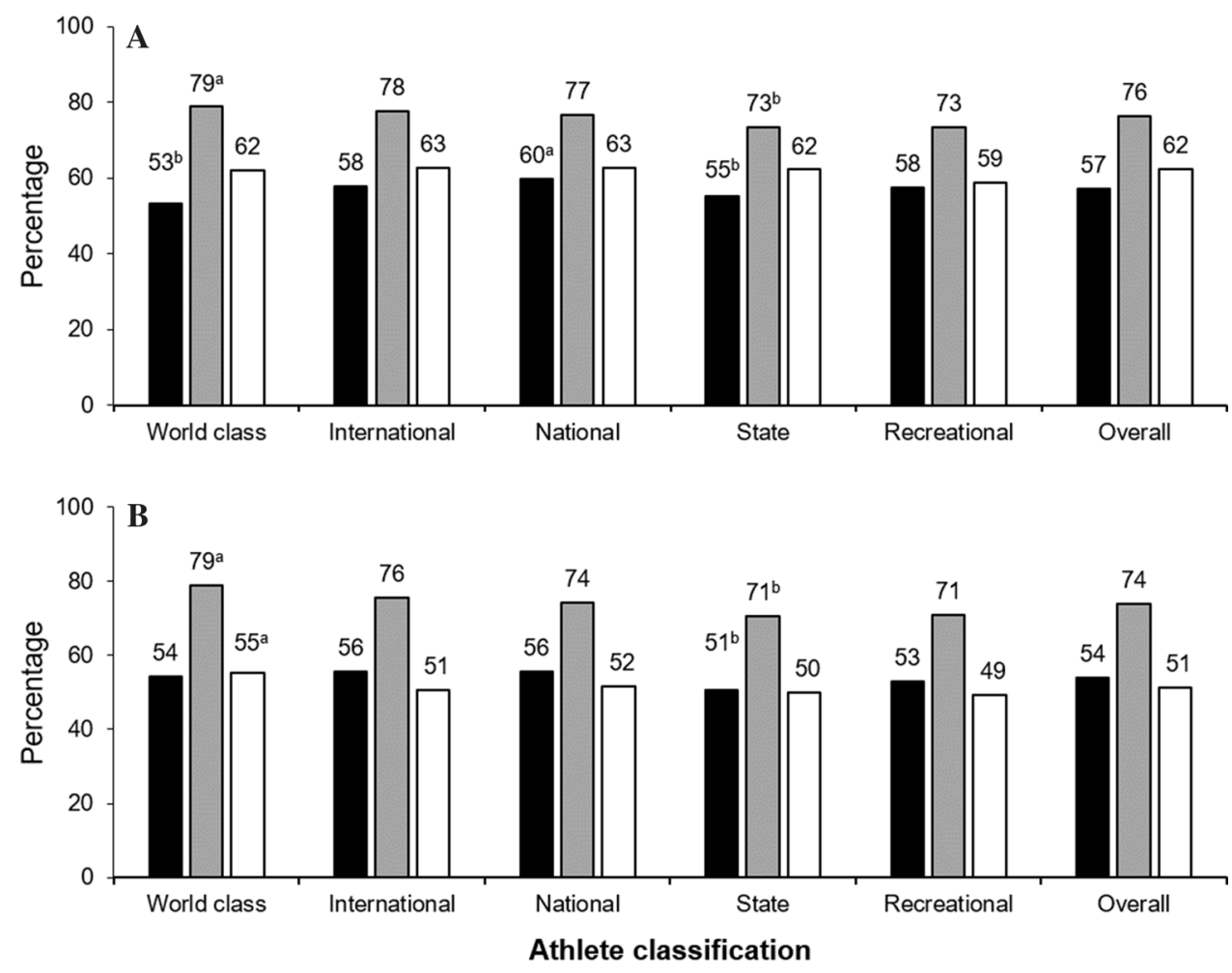

- Technical aCardiovascular 口Strength 
the knowledge and belief/attitude items were addressed in the first person, rather than the third person, to encourage athletes to respond instinctively to each question. Future studies may investigate similar challenges based on sex, sport "type," geographical influence, and socio-economic and human development index factors. Additionally, a quantitative assessment of athletes' physical qualities postlockdown compared with robust pre-lockdown performance data benchmarking appears prudent to inform practice (i.e., reconditioning) and current/future policy in response to similar disruptions to athlete training.

\section{Conclusion}

Higher classification athletes have superior knowledge and beliefs/attitudes regarding training, although these were ranked predominately as "moderate," suggesting that training-related evidence may not penetrate to a "good" level in all athletes. COVID-19-mediated lockdown compromised nearly all aspects of effective training prescription and periodization (quantity and quality of training across intensity, duration, and frequency) in a manner disadvantageous to lower classification athletes. Lockdown elicited a change in athlete training behaviors, with more training alone and training to promote general health and well-being (i.e., remaining physically active) rather than with sport or discipline specificity, partly because of a lack of resource (e.g., space, equipment, facilities, and multidisciplinary support teams), with such access favoring higher classification athletes. Such training modifications reduced motivation in over half the athletes surveyed (and likely affected mental health in many more). The athlete-practitioner coaching/training interface saw the emergence of digitally mediated "remote"based practices, which were best received by higher classification athletes. It would appear prudent to develop palatable athlete-centered (and practitioner) resources to improve their knowledge and beliefs/attitudes regarding training. Such upskilling would provide athletes with evidence to inform their training modifications in response to germane situations (e.g., COVID-related situations, injury, and illness). Sports organizations or teams should provide necessary resources to athletes, regardless of their classifications, by utilizing online learning and interaction platforms that offer free access to seminars and workshops. In this context, a specific approach to information delivery is required to target athletes across different classifications. The data suggest that stakeholders would benefit from policy and resources (including support) to facilitate remote training with their athletes. Furthermore, consideration of emerging technology (e.g., virtual reality) to diversify (improving motivation and engagement) lockdown-compatible training warrants discussion $[42,43]$. Finally, these data and their context provide a clear rationale for careful consideration and prescription of appropriate sport-specific (re)conditioning upon return to "normal" training and/or competition to mitigate heightened injury risk [5, 8]. Holistically, stakeholders can use the data and discussion to develop policies, processes, and guidelines to facilitate training while keeping athletes safe and healthy (including mental health) during pandemic-related disruption to their training.

Supplementary Information The online version contains supplementary material available at https://doi.org/10.1007/s40279-021-01573-z.

Acknowledgements The COVID-19-ECBATA (Effects of Confinement on knowledge, Beliefs/Attitudes, and Training in Athletes) consortium sincerely thank all who supported the efforts in the accomplishment of this project, especially the athletes (respondents) and sports organizations from $>140$ countries and territories worldwide.

\section{Declarations}

Funding A specific funding was provided by the National Sports Institute of Malaysia for this study.

Conflicts of interest Jad Adrian Washif, Abdulaziz Farooq, Isabel Krug, David B. Pyne, Evert Verhagen, Lee Taylor, Del P. Wong, Iñigo Mujika, Cristina Cortis, Monoem Haddad, Omid Ahmadian, Mahmood Al Jufaili, Ramzi A. Al-Horani, Abdulla Saeed Al-Mohannadi, Asma Aloui, Achraf Ammar, Fitim Arifi, Abdul Rashid Aziz, Mikhail Batuev, Christopher Martyn Beaven, Ralph Beneke, Arben Bici, Pallawi Bishnoi, Lone Bogwasi, Daniel Bok, Omar Boukhris, Daniel Boullosa, Nicola Bragazzi, Joao Brito, Roxana Paola Palacios Cartagena, Anis Chaouachi, Stephen S. Cheung, Hamdi Chtourou, Germina Cosma, Tadej Debevec, Matthew D. DeLang, Alexandre Dellal, Gürhan Dönmez, Tarak Driss, Juan David Peña Duque, Cristiano Eirale, Mohamed Elloumi, Carl Foster, Emerson Franchini, Andrea Fusco, Olivier Galy, Paul B. Gastin, Nicholas Gill, Olivier Girard, Cvita Gregov, Shona Halson, Omar Hammouda, Ivana Hanzlíková, Bahar Hassanmirzaei, Thomas Haugen, Kim Hébert-Losier, Hussein Muñoz Helú, Tomás Herrera-Valenzuela, Florentina J. Hettinga, Louis Holtzhausen, Olivier Hue, Antonio Dello Iacono, Johanna K. Ihalainen, Carl James, Dina C. Janse van Rensburg, Saju Joseph, Karim Kamoun, Mehdi Khaled, Karim Khalladi, Kwang Joon Kim, Lian-Yee Kok, Lewis MacMillan, Leonardo Jose Mataruna-Dos-Santos, Ryo Matsunaga, Shpresa Memishi, Grégoire P. Millet, Imen Moussa-Chamari, Danladi Ibrahim Musa, Hoang Minh Thuan Nguyen, Pantelis T. Nikolaidis, Adam Owen, Johnny Padulo, Jeffrey Cayaban Pagaduan, Nirmala Panagodage Perera, Jorge Pérez-Gómez, Lervasen Pillay, Arporn Popa, Avishkar Pudasaini, Alireza Rabbani, Tandiyo Rahayu, Mohamed Romdhani, Paul Salamh, Abu-Sufian Sarkar, Andy Schillinger, Stephen Seiler, Heny Setyawati, Navina Shrestha, Fatona Suraya, Montassar Tabben, Khaled Trabelsi, Axel Urhausen, Maarit Valtonen, Johanna Weber, Rodney Whiteley, Adel Zrane, Yacine Zerguini, Piotr Zmijewski, Øyvind Sandbakk, Helmi Ben Saad, and Karim Chamari have no conflicts of interest that are directly relevant to the content of this article. 
Availability of data and material All data are stored on institutional servers of the corresponding author and are available on reasonable request. All related survey questionnaires are presented in the main text or within the supplementary material.

Code availability Not applicable.

Author contributions All authors were involved in data collection and manuscript revision and approved the final version of the manuscript.

Ethics approval This study was approved by the Human Research Ethics Committee of the University of Melbourne (HREC no. 2056955.1), Qatar University (QU-IRB 1346-EA/20), and the University of Cassino e Lazio Meridionale $(10,031)$.

Consent to participate All respondents provided informed consent before participating in the survey.

Consent for publication All respondents provided consent for the use of data (anonymous) for research purposes and publications.

Open Access This article is licensed under a Creative Commons Attribution 4.0 International License, which permits use, sharing, adaptation, distribution and reproduction in any medium or format, as long as you give appropriate credit to the original author(s) and the source, provide a link to the Creative Commons licence, and indicate if changes were made. The images or other third party material in this article are included in the article's Creative Commons licence, unless indicated otherwise in a credit line to the material. If material is not included in the article's Creative Commons licence and your intended use is not permitted by statutory regulation or exceeds the permitted use, you will need to obtain permission directly from the copyright holder. To view a copy of this licence, visit http://creativecommons.org/licenses/by/4.0/.

\section{References}

1. Trabelsi K, Ammar A, Masmoudi L, et al. Globally altered sleep patterns and physical activity levels by confinement in 5056 individuals: ECLB COVID-19 international online survey. Biol Sport. 2021;38(4):495-506. https://doi.org/10.5114/biolsport. 2021. 101605.

2. Bok D, Chamari K, Foster C. The pitch invader - COVID-19 cancelled the game: what can science do for us, and what can the pandemic do for science? Int J Sports Physiol Perform. 2020;15(7):917-9. https://doi.org/10.1123/ijspp.2020-0467.

3. Washif JA, Mohd Kassim SFA, Lew PCF, et al. Athlete's perceptions of a 'quarantine' training camp during the COVID-19 lockdown. Front Sports Act Liv. 2021;2: 622858. https://doi.org/ 10.3389/fspor.2020.62285.

4. Stokes KA, Jones B, Bennett M, et al. Returning to play after prolonged training restrictions in professional collision sports. Int J Sports Med. 2020. https://doi.org/10.1055/a-1180-3692.

5. Pillay L, Janse van Rensburg DC, Jansen van Rensburg A, et al. Nowhere to hide: the significant impact of coronavirus disease 2019 (COVID-19) measures on elite and semi-elite South African athletes. J Sci Med Sport. 2019;2020(23):670-9. https://doi. org/10.1016/j.jsams.2020.05.016.
6. Bisciotti G, Eirale C, Corsini A, et al. Return to football training and competition after lockdown caused by the COVID-19 pandemic: medical recommendations. Biol Sport. 2020;37(3):313-9.

7. Chtourou H, Trabelsi K, H'mida C, et al. Staying physically active during the quarantine and self-isolation period for controlling and mitigating the COVID-19 pandemics: A systematic overview of the literature. Front Psychol. 2020. https://doi.org/10.3389/fpsyg. 2020.01708.

8. Jukic I, Calleja-González J, Cos F, et al. Strategies and solutions for team sports athletes in isolation due to COVID-19. Sports. 2020;8(4):56. https://doi.org/10.3390/sports8040056.

9. Ravalli S, Musumeci G. Coronavirus outbreak in Italy: Physiological benefits of home-based exercise during pandemic. J Funct Morphol Kinesiol. 2020;5(2):31. https://doi.org/10.3390/jfmk5 020031.

10. Paoli G, Musumeci G. Elite athletes and COVID-19 lockdown: future health concerns for an entire sector. J Funct Morphol Kinesiol. 2020;5(2):30. https://doi.org/10.3390/jfmk5020030.

11. Maugeri G, Castrogiovanni P, Battaglia G, et al. The impact of physical activity on psychological health during Covid-19 pandemic in Italy. Heliyon. 2020;6(6): e04315. https://doi.org/10. 1016/j.heliyon.2020.e04315.

12. Jagim AR, Luedke J, Fitzpatrick A, et al. The impact of covid19-related shutdown measures on the training habits and perceptions of athletes in the United States: a brief research report. Front Sports Act Liv. 2020;2:623068. https://doi.org/10.3389/fspor. 2020.623068.

13. Hermassi S, Bouhafs EG, Bragazzi NL, et al. Effects of home confinement on the intensity of physical activity during the COVID-19 outbreak in team handball according to country, gender, competition level, and playing position: a worldwide study. Int J Environ Res Public Health. 2021;18:4050. https://doi.org/10. 3390/ijerph18084050.

14. Yousfi N, Bragazzi NL, Briki W, et al. The COVID-19 pandemic: how to maintain a healthy immune system during the lockdowna multidisciplinary approach with special focus on athletes. Biol Sport. 2020;37(3):211-6. https://doi.org/10.5114/biolsport.2020. 95125.

15. Impellizzeri FM, Franchi MV, Sarto F, et al. Sharing information is probably more helpful than providing generic training recommendations on return to play after COVID-19 home confinement. Sci Med Footb. 2020;4(3):169-70. https://doi.org/10.1080/24733 938.2020 .1775436$.

16. Polero P, Rebollo-Seco C, Adsuar JC, et al. Physical activity recommendations during COVID-19: narrative review. Int J Environ Res Public Health. 2021;18:65. https://doi.org/10.3390/ijerph1801 0065 .

17. Meyer T, Mack D, Donde K, et al. Successful return to professional men's football (soccer) competition after the COVID-19 shutdown: a cohort study in the German Bundesliga. Br J Sports Med. 2021;55:62-6.

18. Buckley J, Cameron LD. Automaticity of exercise self-regulatory efficacy beliefs in adults with high and low experience in exercise self-regulation. J Sport Exerc Psychol. 2011;33(3):325-48. https:// doi.org/10.1123/jsep.33.3.325.

19. Toering TT, Elferink-Gemser MT, Jordet G, et al. Self-regulation and performance level of elite and non-elite youth soccer players. J Sports Sci. 2009;27(14):1509-17. https://doi.org/10.1080/02640 410903369919. 
20. Zimmerman BJ, Moylan AR. Self-regulation: where metacognition and motivation intersect. In: Hacker DJ, Dunlosky J, Graesser AC, editors. Handbook of metacognition in education. New York, NY: Routledge; 2009. p. 299-315.

21. Hurst P, Schipof-Godart L, Szabo A, et al. The placebo and nocebo effect on sports performance: a systematic review. Eur J Sport Sci. 2020;20(3):279-92. https://doi.org/10.1080/17461391. 2019.1655098 .

22. Vaara JP, Vasankari T, Koski HJ, et al. Awareness and knowledge of physical activity recommendations in young adult men. Front Public Health. 2019;7:310. https://doi.org/10.3389/fpubh.2019. 00310.

23. Poobalan AS, Aucott LS, Clarke A, et al. Physical activity attitudes, intentions and behaviour among 18 to 25 year olds: a mixed method study. BMC Public Health. 2012;12(1):640.

24. Affuso O, Cox TL, Durant NH, et al. Attitudes and beliefs associated with leisure-time physical activity among African American adults. Ethn Dis. 2011;21:63-7.

25. Samuel RD, Tenenbaum G, Galily Y. The 2020 coronavirus pandemic as a change-event in sport performers' careers: conceptual and applied practice considerations. Front Psychol. 2020;11: 567966. https://doi.org/10.3389/fpsyg.2020.567966.

26. Gliem J, Gliem R. Calculating, interpreting, and reporting cronbach's alpha reliability coefficient for likert-type scales. Midwest Research to Practice Conference in Adult, Continuing, and Community Education: 2003.

27. Kaftandjieva, F. Methods for setting cut scores in criterion-referenced achievement tests. In: Cito, Arnhem: EALTA 2010, 170

28. Khan Khan YH, Sariff A, Khan AH, et al. Knowledge, attitude and practice (KAP) survey of osteoporosis among students of a tertiary institution in Malaysia. Trop J Pharm Res. 2014;13(1):155-62.

29. Buchheit M, Laursen PB. High-intensity interval training, solutions to the programming puzzle: Part II: anaerobic energy, neuromuscular load and practical applications. Sports Med. 2013;43:927-54. https://doi.org/10.1007/s40279-013-0066-5.

30. Mujika I, Padilla S. Scientific bases for precompetition tapering strategies. Med Sci Sports Exerc. 2003;35:1182-7. https://doi.org/ 10.1249/01.MSS.0000074448.73931.11.

31. McMaster DT, Gill N, Cronin J, et al. The development, retention and decay rates of strength and power in elite rugby union, rugby league and American football: a systematic review. Sports Med. 2013;43:367-84. https://doi.org/10.1007/s40279-013-0031-3.

32. Izquierdo M, Ibañez J, González-Badillo JJ, et al. Detraining and tapering effects on hormonal responses and strength performance. J Strength Cond Res. 2007;21(3):768-75. https://doi.org/10.1519/ 00124278-200708000-00019.

33. Spiering BA, Mujika I, Sharp MA, et al. Maintaining physical performance: the minimal dose of exercise needed to preserve endurance and strength over time. J Strength Cond Res. 2021. https://doi.org/10.1519/JSC.0000000000003964.
34. di Fronso S, Costa S, Montesano C, et al. The effects of COVID19 pandemic on perceived stress and psychobiosocial states in Italian athletes. Int Sport Exerc Psychol. 2020. https://doi.org/10. 1080/1612197X.2020.1802612.

35. Edwards AM, Dutton-Challis L, Cottrell D, et al. Impact of active and passive social facilitation on self-paced endurance and sprint exercise: encouragement augments performance and motivation to exercise. BMJ Open Sport Exerc Med. 2018;4(1):368. https:// doi.org/10.1136/bmjsem-2018-000368.

36. Hettinga FJ, Konings MJ, Pepping G-J. The science of racing against opponents: affordance competition and the regulation of exercise intensity in head-to-head competition. Front Physiol. 2017;8:118. https://doi.org/10.3389/fphys.2017.00118.

37. Haugen T, Seiler S, Sandbakk Ø. et al. The training and development of elite sprint performance: an integration of scientific and best practice literature. Sports Med Open. 2019; 5: 44. https://doi. org/10.1186/s40798-019-0221-0

38. Zinner C, Matzka M, Leppich R, et al. The impact of the German strategy for containment of coronavirus sars-cov-2 on training characteristics, physical activity and sleep of highly trained kayakers and canoeists: a retrospective observational study. Front Sports Act Living. 2020;2: 579830. https://doi.org/10.3389/fspor.2020. 579830.

39. Muriel X, Courel-Ibáñez J, Cerezuela-Espejo V, et al. Training load and performance impairments in professional cyclists during COVID-19 lockdown. Int J Sports Physiol Perform. 2020;1:1-4. https://doi.org/10.1123/ijspp.2020-0501.

40. Mon-López D, de la Rubia RA, Hontoria Galán M, et al. The impact of Covid-19 and the effect of psychological factors on training conditions of handball players. Int J Environ Res Publ Health. 2020;17:6471. https://doi.org/10.1016/j.physbeh.2020. 113148.

41. Czeisler MÉ, Lane RI, Wiley JF, et al. Follow-up survey of US adult reports of mental health, substance use, and suicidal ideation during the COVID-19 pandemic. JAMA Netw Open. 2021;4(2):e2037665.

42. Menting SGP, Hendry DT, Schiphof-Godart L, et al. Optimal development of youth athletes toward elite athletic performance: how to coach their motivation, plan exercise training, and pace the race. Front Sports Act Liv. 2019;1:14. https://doi.org/10.3389/ fspor.2019.00014.

43. Ammar A, Bouaziz B, Trabelsi K, et al. Applying digital technology to promote active and healthy confinement lifestyle during pandemics in the elderly. Biol Sport. 2021;38(3):391-6. https:// doi.org/10.5114/biolsport.2021.100149.

44. World Athletics. https://www.worldathletics.org/records/by-categ ory/world-records. Accessed 13 Oct 2021. 


\section{Authors and Affiliations}

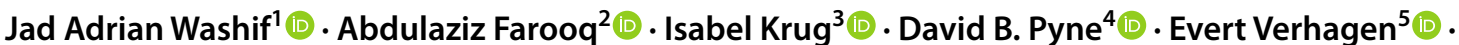

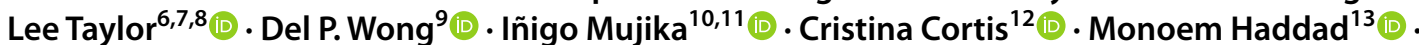
Omid Ahmadian ${ }^{14}$. Mahmood Al Jufaili ${ }^{15}$ (1) Ramzi A. Al-Horani ${ }^{16}$ (1) . Abdulla Saeed Al-Mohannadi ${ }^{17}$ (1) .

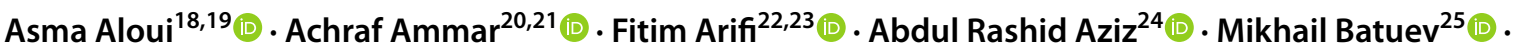
Christopher Martyn Beaven ${ }^{26}$ (1) Ralph Beneke ${ }^{27} \cdot$ Arben Bici $^{28} \cdot$ Pallawi Bishnoi $^{29} \cdot$ Lone Bogwasi $^{30,31}$.

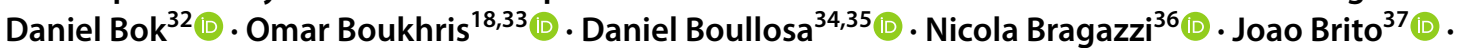
Roxana Paola Palacios Cartagena ${ }^{38} \cdot$ Anis Chaouachi $^{39,40}$. Stephen S. Cheung ${ }^{41}$ (1) Hamdi Chtourou ${ }^{18,33}$. Germina Cosma ${ }^{42}$ (1) Tadej Debevec ${ }^{43,44}$ (1) - Matthew D. DeLang ${ }^{45}$. Alexandre Dellal ${ }^{46,47}$. Gürhan Dönmez ${ }^{48}$ (1) Tarak Driss ${ }^{21}$ (1) Juan David Peña Duque ${ }^{49} \cdot$ Cristiano Eirale $^{50} \cdot$ Mohamed Elloumi $^{51}$ (1) Carl Foster $^{52}$.

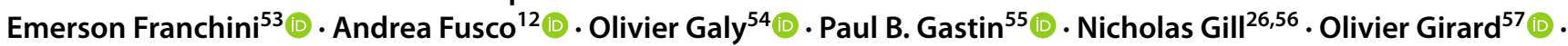
Cvita Gregov $^{32}$. Shona Halson ${ }^{58}$ (1) - Omar Hammouda ${ }^{59,60}$. Ivana Hanzlíková26 (i) - Bahar Hassanmirzaei ${ }^{61,62(1)}$.

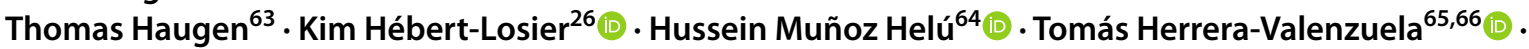

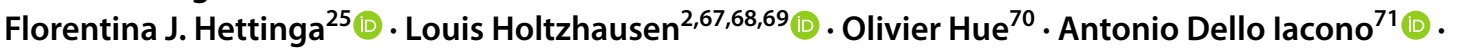
Johanna K. Ihalainen ${ }^{72}$ (D) Carl James ${ }^{1}$. $\cdot$ Dina C. Janse van Rensburg ${ }^{68,73}$ (D) $\cdot$ Saju Joseph $^{74} \cdot$ Karim Kamoun $^{39}$.

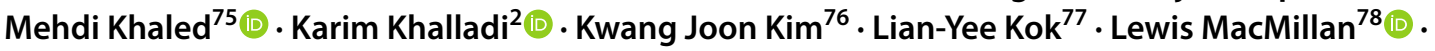
Leonardo Jose Mataruna-Dos-Santos ${ }^{79,80,81}$ ( Ryo Matsunaga ${ }^{82,83} \cdot$ Shpresa Memishi $^{84} \cdot$ Grégoire P. Millet $^{85}$ (1) Imen Moussa-Chamari ${ }^{13}$ (C) Danladi Ibrahim Musa ${ }^{86}$ (b) Hoang Minh Thuan Nguyen ${ }^{87} \cdot$ Pantelis T. Nikolaidis $^{88}$ (1). Adam Owen ${ }^{89,90}$. Johnny Padulo ${ }^{91}$ (1) . Jeffrey Cayaban Pagaduan ${ }^{92} \cdot$ Nirmala Panagodage Perera ${ }^{93,94,95}$ (1) . Jorge Pérez-Gómez ${ }^{96}$ - Lervasen Pillay ${ }^{68,97}$ (1) Arporn Popa ${ }^{98}$. Avishkar Pudasaini ${ }^{99} \cdot$ Alireza Rabbani $^{100}{ }^{(1)}$. Tandiyo Rahayu ${ }^{101}$ (D) Mohamed Romdhani ${ }^{18}$ (D) Paul Salamh ${ }^{102} \cdot$ Abu-Sufian Sarkar ${ }^{103} \cdot$ Andy Schillinger ${ }^{104}$. Stephen Seiler ${ }^{105}$ (1) Heny Setyawati ${ }^{101}$. $\cdot$ Navina Shrestha ${ }^{99,106} \cdot$ Fatona Suraya $^{101}$ - Montassar Tabben ${ }^{2}$. Khaled Trabelsi ${ }^{33,107}$ (1) Axel Urhausen ${ }^{108,109,110} \cdot$ Maarit Valtonen $^{111}$ (1) . Johanna Weber ${ }^{112,113}$ (1) .

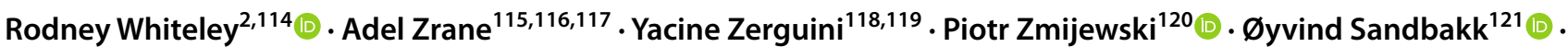
Helmi Ben Saad ${ }^{122,123}$ (D) Karim Chamari²

Jad Adrian Washif jad@isn.gov.my

1 Sports Performance Division, Institut Sukan Negara Malaysia (National Sports Institute of Malaysia), Kuala Lumpur, Malaysia

2 Aspetar, Orthopaedic and Sports Medicine Hospital, FIFA Medical Centre of Excellence, Doha, Qatar

3 Melbourne School of Psychological Sciences, The University of Melbourne, Melbourne, VIC, Australia

4 Research Institute for Sport and Exercise, University of Canberra, Canberra, ACT, Australia

5 Department of Public and Occupational Health, Amsterdam Collaboration on Health \& Safety in Sports, Amsterdam Movement Sciences, Amsterdam UMC, Vrije Universiteit Amsterdam, Amsterdam, The Netherlands

6 School of Sport, Exercise and Health Sciences, National Centre for Sport and Exercise Medicine (NCSEM), Loughborough University, Loughborough, UK

7 Human Performance Research Centre, University of Technology Sydney, Sydney, Australia

8 Sport \& Exercise Discipline Group, Faculty of Health, University of Technology Sydney, Sydney, NSW, Australia

9 School of Nursing and Health Studies, The Open University of Hong Kong, Ho Man Tin, Hong Kong
10 Department of Physiology, Faculty of Medicine and Nursing, University of the Basque Country, Leioa, Basque Country, Spain

11 Exercise Science Laboratory, Faculty of Medicine, School of Kinesiology, Universidad Finis Terrae, Santiago, Chile

12 Department of Human Sciences, Society and Health, University of Cassino and Lazio Meridionale, Cassino, Italy

13 Physical Education Department, College of Education, Qatar University, Doha, Qatar

14 Medical Committee of Tehran Football Association, Tehran, Iran

15 Emergency Medicine Department, Sultan Qaboos University Hospital, Alkhoudh, Oman

16 Department of Exercise Science, Yarmouk University, Irbid, Jordan

17 World Innovation Summit for Health (WISH), Qatar Foundation, Doha, Qatar

18 Physical Activity, Sport \& Health Research Unit (UR18JS01), National Sport Observatory, Tunis, Tunisia

19 High Institute of Sport and Physical Education, University of Gafsa, Gafsa, Tunisia

20 Institute of Sport Sciences, Otto-Von-Guericke University, 39104 Magdeburg, Germany

21 Interdisciplinary Laboratory in Neurosciences, Physiology and Psychology: Physical Activity, Health and Learning 
(LINP2), UFR STAPS, UPL, Paris Nanterre University, Nanterre, France

22 Physical Culture, Sports and Recreation, College Universi, Pristina, Kosovo

23 Faculty of Physical Education and Sport, University of Tetova, Tetovo, North Macedonia

24 Sport Science and Sport Medicine, Singapore Sport Institute, Sport Singapore, Singapore, Singapore

25 Department of Sport, Exercise and Rehabilitation, Northumbria University, Newcastle upon Tyne, UK

26 Division of Health, Engineering, Computing and Science, Te Huataki Waiora School of Health, University of Waikato, Tauranga, New Zealand

27 Division of Medicine, Training and Health, Institute of Sport Science and Motology, Philipps University Marburg, Marburg, Germany

28 Applied Motion Department, Institute of Sport Research, Sports University of Tirana, Tirana, Albania

29 Physiotherapy Department, Minerva Punjab Academy and Football Club, Mohali, Punjab, India

30 Department of Orthopedics, Nyangabgwe Hospital, Francistown, Botswana

31 Botswana Football Association Medical Committee, Gaborone, Botswana

32 Faculty of Kinesiology, University of Zagreb, Zagreb, Croatia

33 High Institute of Sport and Physical Education, University of Sfax, Sfax, Tunisia

34 INISA, Federal University of Mato Grosso do Sul, Campo Grande, Brazil

35 Sport and Exercise Science, James Cook University, Townsville, QLD, Australia

36 Laboratory for Industrial and Applied Mathematics (LIAM), Department of Mathematics and Statistics, York University, Toronto, ON M3J 1P3, Canada

37 Portugal Football School, Portuguese Football Federation, Oeiras, Portugal

38 Facultad de Ciencias del Deporte, Universidad de Extremadura, Cáceres, Spain

39 Tunisian Research Laboratory, Sport Performance Optimisation, National Center of Medicine and Science in Sports (CNMSS), Tunis, Tunisia

40 Sports Performance Research Institute New Zealand, AUT University, Auckland, New Zealand

41 Department of Kinesiology, Brock University, St. Catharines, ON, Canada

42 Faculty of Physical Education and Sport, University of Craiova, Craiova, Romania

43 Faculty of Sport, University of Ljubljana, Ljubljana, Slovenia

44 Department of Automation, Biocybernetics and Robotics, Jozef Stefan Institute, Ljubljana, Slovenia

45 Right to Dream Academy, Old Akrade, Ghana
46 Sport Science and Research Department, Centre Orthopédique Santy, FIFA Medical Centre of Excellence, Lyon, France

47 Laboratoire Interuniversitaire de Biologie de la Motricité (LIBM EA 7424), Claude Bernard University (Lyon 1), Lyon, France

48 Department of Sports Medicine, Hacettepe University, Ankara, Turkey

49 Al Hilal Football Club, Riyadh, Saudi Arabia

50 Paris Saint Germain FC, Paris, France

51 Health and Physical Education Department, Prince Sultan University, Riyadh, Kingdom of Saudi Arabia

52 Department of Exercise and Sport Science, University of Wisconsin-La Crosse, La Crosse, WI, USA

53 Sport Department, School of Physical Education and Sport, University of São Paulo, São Paulo, Brazil

54 Interdisciplinary Laboratory for Research in Education, EA 7483, University of New Caledonia, Avenue James Cook, 98800 Nouméa, New Caledonia

55 Sport and Exercise Science, School of Allied Health, Human Services and Sport, La Trobe University, Melbourne, VIC, Australia

56 New Zealand All Blacks, New Zealand Rugby, Wellington, New Zealand

57 School of Human Science (Exercise and Sport Science), The University of Western Australia, Perth, WA, Australia

58 School of Behavioural and Health Sciences, McAuley at Banyo, Australian Catholic University, Brisbane, QLD, Australia

59 Interdisciplinary Laboratory in Neurosciences, Physiology and Psychology: Physical Activity, Health and Learning (LINP2), UPL, UFR STAPS, Paris Nanterre University, Nanterre, France

60 Research Laboratory, Molecular Bases of Human Pathology, Faculty of Medicine, LR19ES13, University of Sfax, Sfax, Tunisia

61 Sports Medicine Research Center, Neuroscience Institute, Tehran University of Medical Sciences, Tehran, Iran

62 Iran Football Medical Assessments and Rehabilitation Center, IFMARC, Tehran, Iran

63 School of Health Sciences, Kristiania University College, Oslo, Norway

64 Department of Economic-Administrative Sciences, Universidad Autónoma de Occidente, Los Mochis, Sinaloa, México

65 Department of Sport Science and Health, Universidad Santo Tomás, Santiago, Chile

66 University of Santiago of Chile (USACH), Sciences of Physical Activity, Sports and Health School, Santiago, Chile

67 Weil-Cornell Medical College in Qatar, Doha, Qatar

68 Section Sports Medicine, Faculty of Health Sciences, University of Pretoria, Pretoria, South Africa

69 Department of Exercise and Sports Science, University of the Free State, Bloemfontein, South Africa 
70 Laboratoire ACTES, UFR-STAPS, Université Des Antilles, Pointe à Pitre, France

71 School of Health and Life Sciences, University of the West of Scotland, Hamilton, UK

72 Faculty of Sport and Health Sciences, Biology of Physical Activity, University of Jyväskylä, Jyväskylä, Finland

73 Medical Board Member, International Netball Federation, Manchester, UK

74 High Performance Director, Sports Authority of India, Bangalore, India

75 SEHA, Singapore, Singapore

76 Department of Internal Medicine, Yonsei University College of Medicine, Seoul, South Korea

77 Department of Sport Science, Tunku Abdul Rahman University College, Kuala Lumpur, Malaysia

78 Sport Science Department, Fulham Football Club, Fulham, London, UK

79 Centre for Trust, Peace and Social Relation, Coventry University, Coventry, UK

80 Department of Sport Management, Faculty of Management, Canadian University of Dubai, Dubai, United Arab Emirates

81 Programa Avancado de Cultura Contemporanea, Universidade Federal Do Rio de Janeiro, Rio de Janeiro, Brazil

82 Antlers Sports Clinic, Kashima, Ibaraki, Japan

83 Department of Orthopedic Surgery, Tokyo Medical University, Tokyo, Japan

84 Faculty of Physical Education, University of Tetovo, Tetovo, North Macedonia

85 Institute of Sport Sciences, University of Lausanne, Lausanne, Switzerland

86 Department of Human Kinetics and Health Education, Kogi State University, Anyigba, Nigeria

87 Ho Chi Minh City University of Sport, Ho Chi Minh, Vietnam

88 School of Health and Caring Sciences, University of West Attica, Attica, Greece

89 University Claude Bernard Lyon 1, Lyon, France

90 Seattle Sounders Football Club, Seattle, WA, USA

91 Department of Biomedical Sciences for Health, Università Degli Studi di Milano, Milan, Italy

92 School of Health Sciences, College of Health and Medicine, University of Tasmania, Launceston, TAS, Australia

93 Sports Medicine, Australian Institute of Sport, Bruce, ACT, Australia

94 University of Canberra Research Institute for Sport and Exercise (UCRISE), University of Canberra, Bruce, ACT, Australia

95 Nuffield Department of Orthopaedics, Rheumatology and Musculoskeletal Sciences, University of Oxford, Oxford, UK

96 Health, Economy, Motricity and Education (HEME) Research Group, Faculty of Sport Sciences, University of Extremadura, Cáceres, Spain
97 University of Witwatersrand, Wits Institute for Sports Health, Johannesburg, South Africa

98 Health and Sport Science Department, Educational Faculty, Mahasarakham University, Mahasarakham, Thailand

99 Medical Department, All Nepal Football Association (ANFA), Lalitpur, Nepal

100 Department of Exercise Physiology, College of Sport Sciences, University of Isfahan, Isfahan, Iran

101 Faculty of Sport Science, Universitas Negeri Semarang, Semarang, Indonesia

102 Krannert School of Physical Therapy, University of Indianapolis, Indianapolis, IN, USA

103 Bashundhara Kings, Nilphamari, Bangladesh

104 Miskawaan Health Group, Bangkok, Thailand

105 Department of Sports Science and Physical Education, University of Agder, Kristiansand, Norway

106 Physiotherapy Department, BP Eyes Foundation CHEERS Hospital, Bhaktapur, Nepal

107 Research Laboratory: Education, Motricity, Sport and Health, EM2S, LR19JS01, University of Sfax, Sfax, Tunisia

108 Sports Clinic, Centre Hospitalier de Luxembourg, Clinique d'Eich, Luxembourg, Luxembourg

109 Luxembourg Institute of Research in Orthopedics, Sports Medicine and Science, Luxembourg, Luxembourg

110 Human Motion, Orthopedics, Sports Medicine and Digital Methods, Luxembourg Institute of Health, Luxembourg, Luxembourg

111 Research Institute for Olympic Sports, Jyvaskyla, Finland

112 Institute for Sports Science, CAU of Kiel, Kiel, Germany

113 Neurocognition and Action, University of Bielefeld, Bielefeld, Germany

114 University of Queensland, Brisbane, QLD, Australia

115 Department of Physiology and Lung Function Testing, Faculty of Medicine of Sousse, University of Sousse, Sousse, Tunisia

116 Faculty of Sciences of Bizerte, University of Carthage, Bizerte, Tunisia

117 High Institute of Sports, Ksar Said, Tunis, Tunisia

118 FIFA Medical Centre of Excellence Algiers, Algiers, Algeria

119 Medical Committee, Confederation of African Football, Giza, Egypt

120 Jozef Pilsudski University of Physical Education in Warsaw, Warsaw, Poland

121 Centre for Elite Sports Research, Department of Neuromedicine and Movement Science, Norwegian, University of Science and Technology, Trondheim, Norway

122 Laboratoire de Recherche "Insuffisance Cardiaque" (LR12SP09), Hôpital Farhat HACHED, Université de Sousse, Sousse, Tunisie

123 Laboratoire de Physiologie, Faculté de Médicine de Sousse, Université de Sousse, Sousse, Tunisie 